\title{
Considerations About Psychological Development of Children With ADHD (Attention Deficit Hyperactivity Disorder)
}

\author{
Camila Tarif F. Folquitto, Camila L. Rodrigues, Enio R. Andrade, \\ Cristiana C. C. Rocca, Maria Thereza C. C. Souza \\ University of Sao Paulo, Sao Paulo, Brazil
}

\begin{abstract}
Piaget's theory of psychological development can contribute to a better understanding of ADHD (attention deficit hyperactivity disorder). The assumption is that children with ADHD present deficits in the development of the construction of operational notions, such as space-time conceptions and causality. Sixty-nine children (aged 6 to 12) were divided into two groups: children with ADHD and children without diagnosis. According to Piaget's clinical interview, Piagetian tasks were applied. The clinical sample was sub-divided into children who used methylphenidate and non-medicated children. ADHD children showed a tendency to response and reasoning considered most common at developmental levels inferior to the comparison group. Regarding the use of methylphenidate, there was no significant difference of performance between the subgroups. Results may be indicative that the deficits relate mainly to structuring aspects of thinking, and not to performance. Theoretical and practical implications were discussed.
\end{abstract}

Keywords: ADHD (attention deficit hyperactivity disorder), development, cognitive processes, Piagetian tasks

\section{Introduction}

ADHD (attention deficit hyperactivity disorder) is one of the most common disorders in infancy, and one of the main reasons to seek care in mental care child clinics in Brazil (Rohde, Miguel Filho, Benetti, Gallois, \& Kieling, 2004). Over the last decades, executive functions have become important tools for understanding $\mathrm{ADHD}$, and can be defined as the set of skills required to perform voluntary, independent, autonomous, self-organized, and goal-oriented actions. Executive functions account for the acquisition of features such as self-control, planning, and self-regulation, and depend on the individual's experience and socialization. Difficulties in behavioral inhibition and inhibitory control could delay the development of executive skills, and ADHD could be considered a "disorder in the development of the ability to regulate behavior with eyes in the future" (Barkley, 2002). Children with ADHD present the same sequence of phases in cognitive development, albeit slower than children without this diagnosis (Barkley, 1997). For the treatment of ADHD, psychostimulants drugs are usually indicated, such as methylphenidate. Approximately $70 \%$ of the patients under treatment with methylphenidate present improvement at least 50\% of symptoms (Rohde \& Halpern,

Camila Tarif F. Folquitto, Ph.D., Institute of Psychology, University of Sao Paulo.

Camila L. Rodrigues, M.D., Institute of Psychiatry, University of Sao Paulo.

Enio R. Andrade, M.D., Institute of Psychiatry, University of Sao Paulo.

Cristiana C. C. Rocca, Ph.D., Institute of Psychiatry, University of Sao Paulo.

Maria Thereza C. C. Souza, Ph.D., professor, Institute of Psychology, University of Sao Paulo. 
2004).

Piaget's genetic epistemology is an important theoretical approach for the understanding of psychological development, including its cognitive, affective, and moral aspects. The capacity to think before acting, to reflect on several possibilities, and to anticipate, in thought, the outcomes of actions, promote the child's intellectual progress. Because it is logical, operational thinking is reversible, enabling the child to objectively evaluate his/her own attitudes. Thus, an explanatory hypothesis for the symptoms presented by children with ADHD, is that the development of operational skills has lagged, hindering the reflexive processes and regulation of affective interests and valuations. According to this conception, inhibitory control can be related to operational thinking: For to be able to "think before acting", it is necessary to develop the ability to retrieve past events, in light of present events, and anticipate future outcomes.

One of the aspects required for the organization of these sequences of events and movements is time. The conception of time is crucial for the construction of reality in child, as well as the perception of causality. Piaget (1946/1971) defined time is a cognitive conception, formed by physical time (related to the temporal schemes constructed by the individual to understand relations in the physical world, leading to objective temporal measures), and experienced time (considered as the psychological duration of time, the sensation of passage of time).

Deficits in executive functions can result in difficulties to apprehend stretches of time, both in estimation and in reproduction and production of time intervals. Research has shown that children and adolescents with ADHD present specific difficulties to reproduce and estimate time intervals (Rommelse, Oosterlaan, Buitelaar, Faraone, \& Sergeant, 2007; Mullins, Bellgrove, Gill, \& Robertson, 2005; Além-Mar e Silva \& Adda, 2007; Bauermeister et al., 2005; Barkley, 2001). If these assumptions are correct, deficits in the development of the notions of concrete operational thinking, and more specifically, of the conception of time at the concrete operational level, should be observed in these children. It is important to understand such deficits within the context of the child's development and in a theoretical framework which can enable us to consider these difficulties as differentiated developmental pathways.

Furthermore, ADHD diagnosis was recently revised. The DSM-5 considers ADHD as a neurodevelopmental disorder. This revision was based on nearly two decades of research showing that ADHD, although a disorder that begins in childhood, can continue through adulthood for some people (APA (American Psychiatric Association), 2013). Thus, researches in developmental psychology could contribute to the discussion about the development of ADHD children.

\section{Method}

\section{Participants}

The sample consisted of 69 children, aged between six and 12 years old. Of these participants, 37 were patients of the SEPIA (ADHD Clinic of the Child Psychiatry Service) of the IPq-HCFMUSP (Institute of Psychiatry of the Clinical Hospital of the Medical School of the University of São Paulo), and 32 were students from public schools of the City of Sao Paulo, Brazil. The inclusion criteria for the clinical sample were: ADHD diagnostic under the DSM-IV criteria and confirmed through the diagnostic interview K-SADS-PL (Schedule for Affective Disorders and Schizophrenia for School-Age Children/Present and Lifetime Version) (Kaufman et al., 1997). For the control group, absence of psychiatric diagnosis based on K-SADS-PL. Controls with IQ $<70$ 
were excluded. The clinical sample's exclusion criteria were: presence of other psychiatric disorders, except ODD (oppositional defiant disorder), unavailability of family member able to adequately give information about the child, use of psychotropic drugs, except methylphenidate, and IQ $<70$. All the parents responded the condensed version of the Conners questionnaire for parents, and the CBCL (child behavior checklist) (Achenbach, 1991). Seven children were excluded from the study, as they did not meet the criteria of sample composition. Thus, the final sample was composed of 62 children, between six and 12 years old, divided into a clinical sample of children $(n=32)$, and a control group $(n=30)$.

Table 1

Demographic Characteristics and Clinical Variables of the ADHD and Control Groups

\begin{tabular}{|c|c|c|c|c|}
\hline & & $\begin{array}{l}\text { ADHD } \\
(n=32) \\
\text { Mean } S D\end{array}$ & $\begin{array}{l}\text { Normal Controls } \\
(n=30) \\
\text { Mean } S D\end{array}$ & \\
\hline Age & & $9.34 \pm 1.75$ & $9.40 \pm 1.52$ & $\begin{array}{l}t=0.013 \\
p>0.05\end{array}$ \\
\hline Gender & $\begin{array}{l}\text { Female } \\
\text { Male }\end{array}$ & $\begin{array}{l}4(12.5 \%) \\
28(87.5 \%)\end{array}$ & $\begin{array}{l}8(26.7 \%) \\
22(73.3 \%)\end{array}$ & $\begin{array}{l}\chi^{2}=1.991 \\
p>0.05\end{array}$ \\
\hline Education & & $3.15 \pm 1.56$ & $3.10 \pm 1.34$ & $\begin{array}{l}t=-0.151 \\
p>0.05\end{array}$ \\
\hline IQ & & $92.50 \pm 10.60$ & $91.40 \pm 7.59$ & $\begin{array}{l}t=-0.472 \\
p>0.05\end{array}$ \\
\hline Socioeconomic Status & $\begin{array}{l}\mathrm{B} \\
\mathrm{C} \text { and } \mathrm{D}\end{array}$ & $\begin{array}{l}15(46.9 \%) \\
17(53.1 \%)\end{array}$ & $\begin{array}{l}7(23.3 \%) \\
23(76.7 \%)\end{array}$ & $\begin{array}{l}\chi^{2}=3.748 \\
p=0.053\end{array}$ \\
\hline
\end{tabular}

The groups did not differ in terms of age, schooling, gender, and IQ. A statistically significant difference was observed as regards socioeconomic status. The clinical sample presented a tendency to classification at higher socioeconomic level when compared to the control group. The study was presented and approved by the Ethics Committees of the Institute of Psychology and of the Clinical Hospital of the USP (University of Sao Paulo). Participants were informed about the aims and procedures of the project, and the possibility of no participation or abandonment of the study at any time, via the term of free and clarified consent.

\section{Measures}

Intelligence. The participants' IQ was evaluated through two sub-tests of the WASI (Wechsler abbreviated scale of intelligence): vocabulary and matrix reasoning (Weschler, 1999).

Piagetian tasks. With Piaget's clinical interview as a reference, the following Piagetian tasks were applied: conservation of number (Piaget, 1941); criterion change-dichotomy (Inhelder, 1974); succession of perceptible events and simultaneity tasks, and the time of the action proper and interior duration (Piaget, 1946).

In the conservation of number task, six round blue chips and six red chips of the same dimension and size are used. The task began with the presentation of two equal rows of tokens arranged in parallel rows, followed by the transformation of one of the rows, or of both at once. The transformations performed never affected the number, but only the spatial distribution of the elements which were initially in visual correspondence across rows. After each transformation, the child had to judge whether or not the number of elements had changed, and to explain his/her answer.

In the criterion change task-dichotomy, geometrical shapes of different colors, shapes, and dimensions are used (six small red and blue circles; six big red and blue big circles; six small red and blues squares; and six big 
red and blue squares). Researcher randomly placed the pieces on a table and asked the child to describe and classify them, separating them into two boxes.

In the succession of perceptible events task, there is a race between two small cars of different speeds, which start from a common point in the same direction. However, one of the cars moves along a longer course and arrives before the other car, which moves along a spatially shorter course.

In the simultaneity task, objects also move towards the same destination, leaving from the same starting point at different speeds. However, these objects arrive, albeit at different points, at the same time. The researcher asked the child if the objects started at the same time, next if the objects stopped at the same time or at the same moment. If the answer was no, the child was asked which of the objects stopped first.

Finally, in the time of the action proper and interior duration task, the researcher asked the child to draw lines as carefully as possible. After 15 seconds, the child was instructed to stop and draw a new series of lines, this time as quickly as possible. After 15 seconds, the child was again instructed to stop and was asked if one of the stages was longer than the other. In a second phase, the child drew lines as carefully as possible for 15 seconds; then the researcher asked the child to draw new lines as quickly as possible, and to stop after the child felt the same duration of the previous drawing had lapsed. The application of these tasks was recorded (in audio) for subsequent analysis. The tasks investigate whether the child masters operational conceptions, like conservation of number, formation of dichotomized conceptions, and the construction of the operational conception of time (physical and experienced time).

\section{Procedures}

The data analysis was made through two main axes: comparison of performance in the Piagetian tasks of the clinical sample and of the control group; and comparison of children using medication with children non medicated for ADHD. The Piagetian tasks were analyzed by categories, taking into consideration the responses expected at each developmental phase. Each category was scored (1 to 3). Categories expressing more advanced developmental levels were awarded higher scores. In order to test the closeness of agreement of the evaluations, two specialists in Piagetian theory analyzed the interviews and scored the categories.

In the second stage of the task "Time of the action proper and interior duration", in which children were asked to draw lines quickly, stopping when they feel the time was the same as the previous interval (drawing lines slowly for 15 seconds), the children's estimates were grouped in bands of duration, in order to evaluate whether the measured duration was close to the expected 15 seconds or not. Thus, duration between 12 and 18 seconds ( $20 \%$ difference of the total time expected) was considered within what was expected, while other durations were considered estimates outside of the duration band.

\section{Analysis}

The statistical analysis verified the type of distribution of the variables for noncategory data (age, schooling, IQ, sex, score in the Conners, and CBCL questionnaires), through the Kolmogorov-Smirnov test. The data with normal distribution were comparatively analyzed through $t$-tests; data with nonparameter distribution through the Mann-Whitney test. The data were grouped into categories (performance in Piagetian tests and socioeconomic status) were analyzed through the Chi-square test, comparing the two groups. The level of significance adopted was $5 \%(p=0.05)$. 
Table 2

Categories Used for Analyzing the Piagetian Tests

\begin{tabular}{|c|c|c|c|}
\hline Task & Level 1 & Level 2 & Level 3 \\
\hline $\begin{array}{l}\text { Conservation } \\
\text { of number }\end{array}$ & $\begin{array}{l}\text { No conservation responses (The } \\
\text { child believes that the number of } \\
\text { chips changes as a result of } \\
\text { alterations in their spatial position). }\end{array}$ & $\begin{array}{l}\text { Intermediary level between non } \\
\text { conservation and conservation of } \\
\text { quantity. }\end{array}$ & $\begin{array}{l}\text { Operatory notion of quantity } \\
\text { conservation (affirmation that the } \\
\text { number of chips does not depend } \\
\text { on their spatial position). }\end{array}$ \\
\hline nge- & $\begin{array}{l}\text { Shape collections: The child is not } \\
\text { able to separate the shapes into } \\
\text { boxes in any of the three possible } \\
\text { dichotomized criteria, performing } \\
\text { random classification. }\end{array}$ & $\begin{array}{l}\text { Two criteria dichotomy: The child } \\
\text { is able to perceive two out of the three } \\
\text { possible criteria (color/shape/size), } \\
\text { but has difficulty anticipating and } \\
\text { predicting possible classifications. }\end{array}$ & $\begin{array}{l}\text { Three criteria dichotomy: The three } \\
\text { dichotomized criteria are admitted; } \\
\text { the child is able to make different } \\
\text { classifications, anticipating them in } \\
\text { thought. }\end{array}$ \\
\hline $\begin{array}{l}\mathrm{f} \\
\text { vents }\end{array}$ & $\begin{array}{l}\text { No differentiation between the } \\
\text { spatial and temporal data. The child } \\
\text { does not recognize the sequence nor } \\
\text { the movement duration (e.g., "The } \\
\text { car at the front moved longer } \\
\text { because it went farther"). }\end{array}$ & $\begin{array}{l}\text { "Articulated intuition"-The child } \\
\text { gets only one of the aspects right: } \\
\text { He/she recognizes either the } \\
\text { duration or the sequence. Responses } \\
\text { at this level, as well as in the previous } \\
\text { one, are mutually contradictory. }\end{array}$ & $\begin{array}{l}\text { Operatory grouping of succession } \\
\text { and duration-Time and space are } \\
\text { totally dissociated; the child } \\
\text { immediately points out the correct } \\
\text { coordinations, taking into } \\
\text { consideration the difference in speed. }\end{array}$ \\
\hline Sim & $\begin{array}{l}\text { No simultaneity-The duration is } \\
\text { identified as the course followed; } \\
\text { the cars cannot have stopped at the } \\
\text { same time, as one of them "went } \\
\text { farther". The car which is ahead } \\
\text { moved longer. }\end{array}$ & $\begin{array}{l}\text { Beginning of simultaneity-Some } \\
\text { children do not admit simultaneity, } \\
\text { but consider duration proportional } \\
\text { to the course followed. Other } \\
\text { children can notice simultaneity, by } \\
\text { deny same duration. }\end{array}$ & $\begin{array}{l}\text { Immediate coordination of } \\
\text { simultaneity-immediate correct } \\
\text { responses: Children infer } \\
\text { simultaneity of stops, equality of } \\
\text { durations, and vice-versa. }\end{array}$ \\
\hline $\begin{array}{l}\text { Tim } \\
\text { prop } \\
\text { dura }\end{array}$ & $\begin{array}{l}\text { Children answer that drawing lines } \\
\text { quickly takes longer, as they base } \\
\text { their response in the result of the } \\
\text { action (they draw more lines), and } \\
\text { not in the internal perception of } \\
\text { duration. Stage II is frequently not } \\
\text { applicable. }\end{array}$ & $\begin{array}{l}\text { Children consider the fast work to } \\
\text { be longer, but evaluate time } \\
\text { correctly in the second task. Others } \\
\text { feel that the duration of the slow } \\
\text { action "seems" longer than the } \\
\text { other, but cannot measure time } \\
\text { correctly in the second stage. }\end{array}$ & $\begin{array}{l}\text { The answers given by children are } \\
\text { based on introspection ("it seems", } \\
\text { "sort of"...), to express that the } \\
\text { duration of the two tasks is the } \\
\text { same. In the second stage, they are } \\
\text { able to correctly measure the } \\
\text { duration of the interval. }\end{array}$ \\
\hline
\end{tabular}

\section{Results}

\section{Comparison Between the ADHD Group and the Control Group}

In the Piagetian tasks (see Table 3), the control group showed a statistically significant tendency to provide answers and arguments classified at higher levels, when compared to the clinical sample in the following tasks: conservation of discrete quantity (Chips) $\left(\chi^{2}=8.862 ; p=0.003\right)$, simultaneity $\left(\chi^{2}=11.132 ; p=\right.$ $0.004)$, and time of the action proper and interior duration $\left(\chi^{2}=25.859 ; p<0.001\right)$. A statistically significant difference was also found in the duration band $\left(\chi^{2}=14.609 ; p<0.001\right)$ and the sum of all the tasks of the clinical interview $(t=4.749 ; p<0.001)$. The Sequence of Perceived Events task showed a statistically significant difference between groups $\left(\chi^{2}=5.311 ; p=0.070\right)$ and the Dichotomy did not show any statistically significant difference between the groups $\left(\chi^{2}=3.103 ; p>0.05\right)$.

\section{Comparison Regarding Use of Methylphenidate in ADHD Group}

The sociodemographic characteristics of the sub-groups of the clinical sample of children with ADHD (sub-group of medicated children $(n=18)$ versus sub-group of children without medication $(n=14))$ were compared in terms of age, schooling, gender, and socio-economic status, additionally to IQ. Results show that there are no statistically significant differences between the groups in terms of age, schooling, socio-economic classification, and IQ. As for gender, a statistically significant difference was observed $(M W=5.878 ; p=$ 0.015), with high frequency of boys.

In this sample, we obtained high prevalence of one of the sub-types when compared to the others $(75 \%$ of 
the combined sub-type, $19 \%$ inattentive, and $6 \%$ hyperactive), which made the statistical comparison between the different sub-types of ADHD and the performance in the Piagetian tasks impossible. Thus, only the levels of hyperactivity measured through the Conners questionnaires (for parents) and CBCL for the groups with and without medication were correlated. The comparison between the groups demonstrated that there were no statistically significant differences between the levels of hyperactivity measured through the Conners questionnaire, and the percentiles of the "ADHD" item of the CBCL. Comparing the group using methylphenidate with the group without medication, and the performance in the Piagetian tasks, there was no statistically significant difference between the groups, as indicated in Table 4.

Table 3

Comparison of Piagetian Tests

\begin{tabular}{|c|c|c|c|c|}
\hline Piagetian tests & & Cases $(n=32)$ & Controls $(n=30)$ & Comparison between groups \\
\hline \multirow{2}{*}{ Number $^{* * *}$} & N.C./C.I. ${ }^{*}$ & 14 & 3 & \multirow{2}{*}{$\begin{array}{l}\chi^{2}=8.862 \\
p=0.003\end{array}$} \\
\hline & Conservation & 18 & 27 & \\
\hline \multirow{3}{*}{ Dichotomy } & Collections Fig. $^{* *}$ & 9 & 4 & \multirow{3}{*}{$\begin{array}{l}\chi^{2}=3.103 \\
p>0.05\end{array}$} \\
\hline & Dichotomy 2 & 14 & 12 & \\
\hline & Dichotomy 3 & 9 & 14 & \\
\hline \multirow{3}{*}{ Succession } & Level 1 & 14 & 8 & \multirow{3}{*}{$\begin{array}{l}\chi^{2}=5.311 \\
p=0.07\end{array}$} \\
\hline & Level 2 & 16 & 14 & \\
\hline & Level 3 & 2 & 8 & \\
\hline \multirow{3}{*}{ Simultaneity } & Level 1 & 14 & 2 & \multirow{3}{*}{$\begin{array}{l}\chi^{2}=11.132 \\
p=0.004\end{array}$} \\
\hline & Level 2 & 10 & 16 & \\
\hline & Level 3 & 8 & 12 & \\
\hline \multirow{3}{*}{ Time $^{* * * *}$} & Level 1 & 21 & 1 & \multirow{3}{*}{$\begin{array}{l}\chi^{2}=25.859 \\
p<0.001\end{array}$} \\
\hline & Level 2 & 6 & 12 & \\
\hline & Level 3 & 5 & 16 & \\
\hline \multirow{2}{*}{ Duration band } & Within average & 9 & 23 & \multirow{2}{*}{$\begin{array}{l}\chi^{2}=14.609 \\
p<0.001\end{array}$} \\
\hline & Out of average & 23 & 7 & \\
\hline \multirow{2}{*}{ Sum of tests } & Average & 5.46 & 8.03 & $t=4.749$ \\
\hline & $S D$ (Standard Deviation) & 2.40 & 1.77 & $p<0.001$ \\
\hline
\end{tabular}

Notes. ${ }^{*}$ Level 1/Level $2 ;{ }^{* *}$ Level $3 ;{ }^{* * *}$ Conservation of number task; ${ }^{* * * *}$ Time of the action proper and interior duration task.

Table 4

Comparison of Piagetian Tests in the ADHD Group

\begin{tabular}{|c|c|c|c|c|}
\hline Piagetian tests & & On medication $(n=17)$ & Without medication $(n=15)$ & Comparison between groups \\
\hline \multirow{2}{*}{ Number $^{* * *}$} & N.C./C.I. ${ }^{*}$ & 8 & 6 & \multirow{2}{*}{$\begin{array}{l}\chi^{2}=0.161 \\
p>0.05\end{array}$} \\
\hline & Conservation & 9 & 9 & \\
\hline \multirow{3}{*}{ Dichotomy } & Fig. collection ${ }^{* *}$ & 3 & 6 & \multirow{3}{*}{$\begin{array}{l}\chi^{2}=2.137 \\
p>0.05\end{array}$} \\
\hline & Dichotomy 2 & 9 & 5 & \\
\hline & Dichotomy 3 & 5 & 4 & \\
\hline \multirow{3}{*}{ Succession } & Level 1 & 5 & 9 & \multirow{3}{*}{$\begin{array}{l}\chi^{2}=4.034 \\
p>0.05\end{array}$} \\
\hline & Level 2 & 10 & 6 & \\
\hline & Level 3 & 2 & 0 & \\
\hline \multirow{3}{*}{ Simultaneity } & Level 1 & 5 & 9 & \multirow{3}{*}{$\begin{array}{l}\chi^{2}=3.130 \\
p>0.05\end{array}$} \\
\hline & Level 2 & 7 & 3 & \\
\hline & Level 3 & 5 & 3 & \\
\hline \multirow{3}{*}{$\operatorname{Time}^{* * * *}$} & Level 1 & 10 & 11 & \multirow{3}{*}{$\begin{array}{l}\chi^{2}=0.792 \\
p>0.05\end{array}$} \\
\hline & Level 2 & 4 & 2 & \\
\hline & Level 3 & 3 & 2 & \\
\hline \multirow{2}{*}{ Duration band } & Within average & 13 & 10 & \multirow{2}{*}{$\begin{array}{l}\chi^{2}=0.379 \\
p>0.05\end{array}$} \\
\hline & Out of average & 4 & 5 & \\
\hline \multirow{2}{*}{ Sum of tests } & Average & 6.05 & 4.80 & $t=-1.505$ \\
\hline & $S D$ & 2.35 & 2.36 & $p>0.05$ \\
\hline
\end{tabular}

Notes. ${ }^{*}$ Level $1 /$ Level2; ${ }^{* *}$ Level $3 ;{ }^{* * *}$ Conservation of number task; ${ }^{* * * *}$ Time of the action proper and interior duration task. 


\section{Discussion}

The general assumption in this study was that children with ADHD between six and 12 years of age would present delay in the development of operational notions, especially the conception of time, when compared to a group of children without any diagnosis and under the same socio-demographic conditions. Results obtained corroborate this assumption, since the statistical analysis found significant differences in the comparison between the groups for nearly the totality of the Piagetian tasks applied. The implication is that, in general terms, in operational tasks, children with ADHD, more frequently than children without this diagnosis, evidenced thinking orientation responses that are characteristic of pre-operational thinking, i.e., they experience difficulties in anticipating hypothesis at the mental level and in establishing strategies, as this kind of thinking is not sustained beyond the immediate experience, lacking reversibility and flexibility.

These results are in tandem with the results found in the literature (Campos, 2007; Brown, Borden, Schleser, Clingerman, \& Orenczuk, 1985; Borden, Brown, Wynne, \& Schleser, 1987) of studies in which differences were observed between hyperactive and not hyperactive children in the performance of Piagetian tasks of quantity conservation (discrete quantities) and substance (continuous quantities). Therefore, the notion of conservation, essential for the construction of operational thinking, seems to be impaired in these children. Children with ADHD showed a tendency to respond more impulsively, prioritizing configurations perceived at the moment, and were unable, therefore, to achieve conservatory thinking (in which quantities are unchanged), which is typical of the concrete operational stage of development. There was also a tendency among these children to experience difficulties in measuring stretches of time: When they were supposed to interrupt the task at a time which they felt was the same as the previous one, the children of the clinical sample experienced more difficulty performing the task; they either overestimated the duration, interrupting the drawing after many seconds, or they had a tendency to estimate very short stretches of time (e.g., they drew for five seconds and stated that the same 15 seconds of the initial task had lapsed).

In this study, children with ADHD experienced deficits in the construction of the operational conception of time, both physical and experienced time, since both depend on the acquisition of adequate constructions of operational thinking, such as conservation and reversibility. These deficits result in difficulties for the child to adapt to contexts in which the objective perception of time passage is of the essence. Therefore, the construction of the conception of time (physical and experienced) is also a key aspect for the construction of the notion of self, which enables an individual to perceive himself as such, inserted in a space-time context.

Some of the main symptoms of children with ADHD are agitation, hyperactivity, and impulsivity. Based on the results which evidence that children suffering from this disorder experience difficulties in reaching the operational level, it is possible to infer that children with ADHD may experience difficulties to "think before they act", as their thinking cannot fully transcend the present moment, thus anticipating future outcomes or relying on past experience. Therefore, the possible deficits in the construction of the conception of time found in children with ADHD would necessarily result in impairment in the construction of the notion of causality, owing to this difficulty to go beyond the perception of the present moment. Consequently, these children may present actions described as hyperactive and impulsive.

Therefore, this study has demonstrated that, at least in some specific domains, children with ADHD experience some delay in the acquisition of operational notions of thinking, such as quantity, the conception of time, conservation, and reversibility. More in depth studies are required to investigate if the operational deficits 
observed can also result in difficulties that impair global logical thinking, or if there are specific domains and conceptions that are impaired in hyperactive children, relating them to the symptoms exhibited. The non-significance observed in the change of criterion-dichotomy task when we compared children with ADHD and the control group, at least in the sample collected, evidence that diagnosed children and children of the control group performed similarly. This task seems to have been a special challenge for all the children in this study. If we consider the mean age of the sample (about 9.37 years old), according to the literature (Inhelder, 1974), one would expect a predominance of responses classified at level III, characteristic of concrete operational thinking, which was not observed in this sample. However, the children in the control group, who did experience difficulties in this task, performed better in interviews of other tasks that sought to verify conception of time, thus demonstrating that they possess a better operational notion of time, which was not observed in the children with ADHD. On the contrary, they seemed to experience more difficulty in the tasks related to this domain.

The question is what happens to children with ADHD that could account for a delay in the development of operational conceptions of time. Is there really a delay in the development of operational notions, or is their performance, below expected, merely a consequence of their high level of agitation and inability to adequately focus their attention, which when controlled with medication (via psychotropic drugs), would enable these children to resort to their already constructed, albeit "camouflaged", and operational notions?

Several studies have demonstrated an improvement in performance of children with ADHD in intelligence tests, after the use of methylphenidate (Barkley, 2002; Campbell, Douglas, \& Morgenstern, 1971; Szobot, Ketzer, Parente, Biederman, \& Rohde, 2004). However, when it comes to tasks aimed at evaluating the process of development, as is the case of Piagetian tasks, is the medication producing effects, at least immediate effects, in the development of these children's cognitive structuring?

In an attempt to answer these questions, the performance of children with ADHD using methylphenidate in the Piagetian tasks was compared with the performance of children not using any medication to control the disorder. The results showed that the non significance observed may be indicative that the deficits relate mainly to structuring aspects of thinking, and not to performance. Improvement of attention focus brought about by the medication did not have an effect, in this case, in the cognitive structuring of children with ADHD. It can therefore be concluded that medication treatment may be a necessary aspect, although not sufficient to boost the development of children with ADHD. This points to the need to consider alternative intervention which includes and goes beyond pharmacological treatment.

From a constructivist standpoint stemming from the Piagetian theory, psychological development takes place through the meaningful interaction of the subject with the surrounding environment, with the contact with objects that lead to progressively more advanced cognitive and affective regulation and balance. One hypothesis for the fact that children with ADHD present deficits in the development of operational notions is that their difficulty to concentrate and high level of agitation might result in a less meaningful interaction with objects (concrete, abstract, human beings, books, toys, etc.) from the cognitive point of view. And this, because of this incapacity to focus the attention long enough on a certain object, as well as to the difficulty of thinking before acting, of going beyond the realm of physical experience, which enables, through the interaction with objects, the establishment of logical-mathematical experiences that allow for abstraction of the effect of actions and extracting significance from their own actions. ADHD children generally are able to perform successfully in the present, they "can do", but they have difficulty recognizing the actions required to trigger the means that 
leads to a successful end. From this inadequate interaction with the environment, children with ADHD showed more difficulties in the construction of cognitive skills, such as the conception of time and logical-operational capacity.

During the developmental process, the dialectic interaction of two important aspects that determine action can be observed: procedures and structures. This is an inseparable pair and is present in all behavior, even if the individual is not aware of its existence. In the child's interaction with the objects, any strategy adopted requires procedures which necessarily relate back to cognitive structuring that are already known, or that are yet to be discovered by the child. Conversely, procedures are practical actions that lead to the acquisition of new structures. This independent nature of procedures and structures enables the continuous construction of new acquisitions, fostering development (Inhelder \& Piaget, 1979). From the differentiation between procedures and structures it can be concluded that results in Piagetian tasks, in which a cognitive procedure will not be successful unless it is anchored on operational structures, so that the child will not be able to solve the problem in an operational manner unless he/she understands the causal links involved in the task, a deficit in the development of operational structures was observed in children with ADHD.

It is our view that the above findings trigger new reflections on ADHD, based on a more integrated approach, in which the aspects of psychological development of the child are taken into account both from the theoretical and practical points of view. After all, as mentioned, new strategies that go beyond the medication treatment are necessary, so that during the time in which the child is able to focus attention, he/she is able to perform tasks that are enriching from the epistemic point of view, fostering the development of new abilities which, progressively, will contribute to the construction of more complex structures. Maybe this study can contribute to future investigations on the topic, seeking to more specifically ascertain how developmental psychology can contribute to the development of intervention and support strategies for ADHD.

According to Piaget (1971), action boosts development in the interaction with objects leading to progressively more complex balances. The construction of significance for actions is, therefore, at the core of psychological behavior. The child must be allowed to act in the world, but for these actions to represent a rich developmental process, we must foster an environment that on the one hand, respects the needs and rhythm of each child, and on the other, constitutes a challenging environment susceptible to foster the interest of children in learning, in a process of development which ultimately can aid the construction of a curious, inquisitive individual, in constant growth and transformation.

\section{References}

Achenbach, T. M. (1991). Manual for the child behavior checklist. Burlington: University of Vermont, Department of Psychiatry.

Além-mar e Silva, L. C., \& Adda, C. C. (2007). Aspectos cognitivos relacionados à noção de intervalos de tempo (Cognitive aspects related to the notion of time intervals). Jornal Brasileiro de Psiquiatria, 56(2), 120-126.

APA (American Psychiatric Association). (1994). Diagnostic and statistical manual of mental disorders (DSM-IV) (4th ed.). Washington, D.C.: APA.

Barkley, R. A. (1997). Behavioral inhibition, sustained attention, and executive functions: Constructing a unifying theory of ADHD. Psychological Bulletin, 121(1), 65-94.

Barkley, R. A. (2001). Executive functioning, temporal discounting, and sense of time in adolescents with attention deficit hyperactivity disorder (ADHD) and oppositional defiant disorder (ODD). Journal of Abnormal Child Pshychology, 29(6), 541-556.

Barkley, R. A. (2002). Transtorno de déficit de atenção/hiperatividade (TDAH) guia completo para pais, professores e profissionais de saude (Attention deficit hyperactivity disorder (ADHD) complete guide to parents, teachers and health professional). Porto Alegre: Artmed. 
Bauermeister, J. J., Barkley, R. A., Martinez, J. V., Cumba, E., Ramirez, R. R., Reina, G., .. Salas, C. C. (2005). Time estimation and performance on reprodution tasks in subtypes of children with attention deficit hyperactivity disorder. Journal of Clinical Child \& Adolescent Psychology, 34(1), 151-162.

Borden, K. A., Brown, R. T., Wynne, M. E., \& Schleser, R. (1987). Piagetian Conservation and response to cognitive therapy in attention déficit disordered children. Journal of Child Psychology and Pshychiatry, 28(5).

Brown, R. T., Borden, K. A., Schleser, R., Clingerman, S., \& Orenczuk, S. (1985). The performance of attention-deficit disordered and normal children on conservation tasks. The Journal of Genetic Psychology, 146(4).

Campbell, S. B., Douglas, V. I., \& Morgenstern, G. (1971). Cognitive stiles in hyperactive children and the effect of methylphenidate. Journal of Child Psychology Psychiatry, 12, 55-67.

Campos, L. G. A. C. (2007). Avaliação do pensamento lógico em pacientes com transtorno de déficit de atenção com ou sem hiperatividade (TDAH) (Evaluation of logical thinking in attention deficit hyperactivity disorder (ADHD)) (Dissertação de Mestrado, Universidade Estadual Paulista Júlio de Mesquita Filho, UNESP).

Inhelder, B. (1977). Aprendizagem e estruturas do conhecimento. São Paulo: Saraiva.

Inhelder, B., \& Piaget, J. (1979). Procédures et structures. Archives de Psychologie, XLVII(181), 165-176.

Kaufman, J., Birmaher, B., Brent, D., Rao, U., Flynn, C., Moreci, P., ... Ryan N. (1997). Schedule for affective disorders and schizophrenia for school-age children-Present and lifetime version (KSADS-PL): Initial reliability and validity data. Journal of the American Academy of Child and Adolescent Psychiatry, 36, 980-988.

Mullins, C. B. A., Bellgrove, M. A., Gill, M., \& Robertson, I. H. (2005). Variability in time reproduction: Difference in ADHD combined and inattentive subtypes. Journal of American Academy of Child and Adolescent Psychiatry, 44(2).

Piaget, J. (2005). A representação do mundo na criança (The child's conception of the world). São Paulo: Ideias \& letras.

Piaget, J. (1952). The child's conception of number (p. 258). New York: Basic Books.

Piaget, J. (1946/1971). The child's conception of time. New York: Ballentine.

Rohde, L. A., \& Halpern, R. (2004). Transtorno de déficit de atenção/hiperatividade: Atualização (Attention deficit hyperactivity disorder: Update). Jornal de Pediatria, 80(2).

Rohde, L. A., Miguel Filho, E. C., Benetti, L., Gallois, C., \& Kieling, C. (2004). Transtorno de déficit de atenção/hiperatividade na infância e na adolescência: Considerações clínicas e terapêuticas (Attention deficit hyperactivity disorder in childhood and adolescence: Clinical and terapeutical considerations). Revista de Psiquiatria Clínica, 31(3), 124-131.

Rommelse, N. N., Oosterlaan, J., Buitelaar, J., Faraone, S. V., \& Sergeant, J. A. (2007). Time reproduction in children with ADHD and their nonaffected siblings. Journal of American Academy of Child and Adolescent Psychiatry, 46(5), 582-590.

Szobot, C. M., Ketzer, C., Parente, M. A., Biederman, J., \& Rohde, L. A. (2004). The acute effect of methylphenidate in Brazilian male children and adolescents with ADHD: A randomized clinical trial. Journal of Attention Disorders, 8(2).

The Psychological Corporation. (1999). Wechsler abbreviated scale of intelligence manual. San Antonio: Psychological Corporation. 